\title{
Computer-Aided Heat Integration of Biodiesel Production from Chlorella Vulgaris Microalgae
}

\author{
M. Ochoa-García' ${ }^{1}$ L. Tejeda-López ${ }^{1}$, K. Ojeda-Delgado ${ }^{1 *}$, Á. D. González-Delgado² and \\ E. Sánchez-Tuirán \\ 'Department of Chemical Engineering, Process Design and Biomass Utilization Research Group (IDAB), \\ University of Cartagena, Cartagena, Bolívar, Colombia; \\ maria8g@hotmail.com, Intejedal@gmail.com, kojedad@unicartagena.edu.co, esanchezt2@unicartagena.edu.co \\ 2Department of Chemical Engineering, Nanomaterials and Computer Aided Process Engineering \\ Research Group (NIPAC), University of Cartagena, Cartagena, Bolívar, Colombia; \\ agonzalezd1@unicartagena.edu.co
}

\begin{abstract}
Background: Microalgae have gained certain attention globally as feedstock for biodiesel production due to its fast growth rate and high potential yield of bio-fuel. Objectives: This work is focused on applying heat integration by thermal pinch point technique to a third generation biodiesel production process using Chlorella vulgaris as feedstock. Methods/Analysis: This case of study was simulated through commercial industrial process simulation software. A Cascade Diagram (CD) was constructed by defining temperature intervals and performing heat balance around them. The CD provided information about minimum cooling and heating utilities usage and maximum integrated heat exchange. In addition, a HEN was sensitized to achieve utilities targets. Findings: It was found that heat integration reduced cooling utilities and heating utilities by 38.67 and $100 \%$, respectively, which reduces total operating costs when compared to base case. Novelty/Improvement: These results suggested that operating cost of biodiesel production from microalgae can be reduced by performing heat integration that represents an attractive process improvement for making biodiesel cost-competitive with other energy sources.
\end{abstract}

Keywords: Biodiesel, Heat Integration, Pinch Point, Utilities, CAPE

\section{Introduction}

Nowadays, renewable energy sources have become focus of attention for researchers around the world due to depletion of fossil fuels, which provide a large proportion

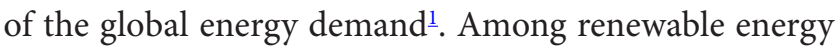
alternatives, bio-fuels have been considered as a promising fuel substituent $\frac{2,3}{3}$. This is attributed to biodiesel environmental characteristics as non-toxic, completely biodegradable and reduced sulfur and carbon monoxide emission ${ }^{4}$. Liquid bio-fuels can be produced from differ- ent type of raw material and are categorized into first, second and third generation 5 . First-generation bio-fuels are obtained from dedicated cultivation of bio-energy crops competing with agricultural lands ${ }^{6}$. Second generation bio-fuels are produced from lingo-cellulosic biomass or animal materials such as corn Stover and animal fat ${ }^{\underline{ }}$. Third generation bio-fuels are produced from aquatic cultivated feedstock $\stackrel{8}{*}$. Microalgae have been highlighted as the most attractive feedstock for third generation production of biodiesel ${ }^{2}$. They have several significant advantages form an environmental point of view as not

${ }^{*}$ Author for correspondence 
requirements of agricultural land for cultivation and are highly productive year-round 10 . Microalgae have a very broad biodiversity, however, Chlorella $s p$. is currently dominating the micro-algal market and is widely used to obtain high-value products as biofuels $s^{11,12}$.

In brief, the process of producing biodiesel from microalgae is based on four major steps: 1. microalgae cultivation, 2. harvesting, 3. algal oil extraction, and 4 . transesterification $\frac{13}{}$. It has been reported that biodiesel production cost from microalgae lies between US \$ 2.38-10.58/1, which must be reduced to enhance its costcompetition with other energy sources ${ }^{14}$. To overcome the techno-economic bottleneck of third generation bio-fuels production, many efforts have been paid on reducing production $\operatorname{costs}^{15}$. In this study, heat integration approach is purposed to address the challenge of high production cost of biodiesel from microalgae attributed to cooling and heating utilities. In addition, a HEN was designed for achieving target temperatures with minimum utilities usage.

\section{Material and Methods}

\subsection{Process Description}

The case of study selected to apply heat integration is the biodiesel production from Chlorella vulgaris microalgae, which was simulated using commercial industrial process simulation software as shown Figure 1. This process is based on the following stages: pre-treatment using glycerol, alkaline transesterification and biodiesel-coproduct separation. The microalgae oil was simulated as a mixture of nine free fatty acids and nine homogeneous triglycerides. The pre-treatment is carried out by injecting $1 \%$ wt. glycerol in a reactor at $200^{\circ} \mathrm{C}$ in presence of $\mathrm{ZnCl}_{2}$ with the aim of avoiding alkaline metals formation and allowing the reusability of glycerol. To remove the resulting water formed during the reaction, the outlet stream of pre-treatment reactor is sent to a flash vessel. Transesterification is a chemical reaction between alcohol and triglycerides to produce biodiesel and glycerol ${ }^{16}$. In

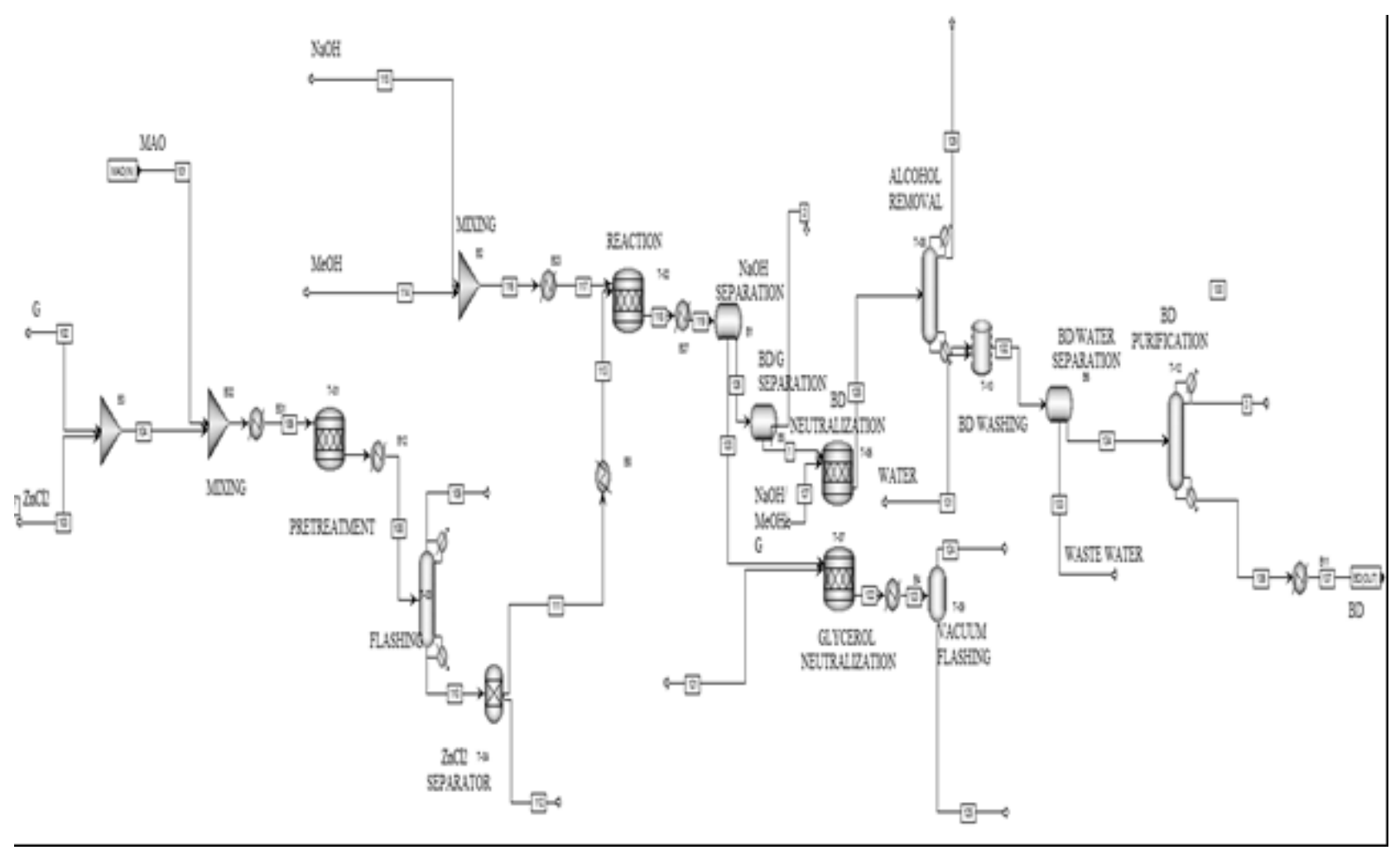

Figure 1. Process diagram of biodiesel production from Chlorella vulgaris microalgae. 
this work, the transesterification reaction takes place into a CSTR reactor at $60^{\circ} \mathrm{C}$, in which methanol is used as initiator and $1 \%$ wt. $\mathrm{NaOH}$ solution is added to the oil-methanol mixture as base catalyst. The glycerol is produced as by-product during the transesterification reactions; hence, decanting is used to separate biodiesel from glycerol. Afterward, glycerol stream is neutralized with sulfuric acid. The resulting biodiesel passes through a distillation unit in order to separate methanol from this bio-fuel. Then, biodiesel stream is rinsed with hot acidulated water and sent to decanting equipment to remove water, catalyzer and other impurities. Finally, biodiesel is subjected to distillation with the aim of obtaining high purity biodiesel (96.5\% wt.).

\subsection{Heat Integration}

Heat integration was performed by thermal pinch diagram technique for biodiesel production process to determine the pinch point and minimum heating and cooling utilities. In brief, hot and cold process streams were identified according to its outlet and inlet temperatures. It was assumed that heat capacity is constant over the operating range and was calculated as an average between heat capacity of inlet and outlet streams. El-Halwagi ${ }^{17}$ sug- gested a minimum temperature difference referred to as driving force of $10-20^{\circ} \mathrm{C}$, hence was set to $10^{\circ} \mathrm{C}$.

The temperatures were organized in ascending order to obtain the lower and upper limits of temperature intervals and the Temperature-Interval Diagram (TID) was constructed with two temperature scales (hot and cold). The scale correspondence was calculated by Eq. 1 .

$$
T=t+\Delta t^{\min }
$$

Vertical arrows were used for TID construction as a representation of each stream whose tail corresponds to its supply temperature () and its head represents its target temperature (). The temperature intervals are represented by horizontal lines. Then, Table of Exchangeable Heat Loads (TEHL) was obtained by determining heatexchange loads of streams in each temperature interval with Eq. 2.

$$
H H_{u, z}=F_{u} C_{p}\left(T_{i}-T_{i-1}\right)
$$

Where and are the temperatures defining temperature intervals. The exchangeable capacity of each cold

\section{Residual heat from preceding interval}

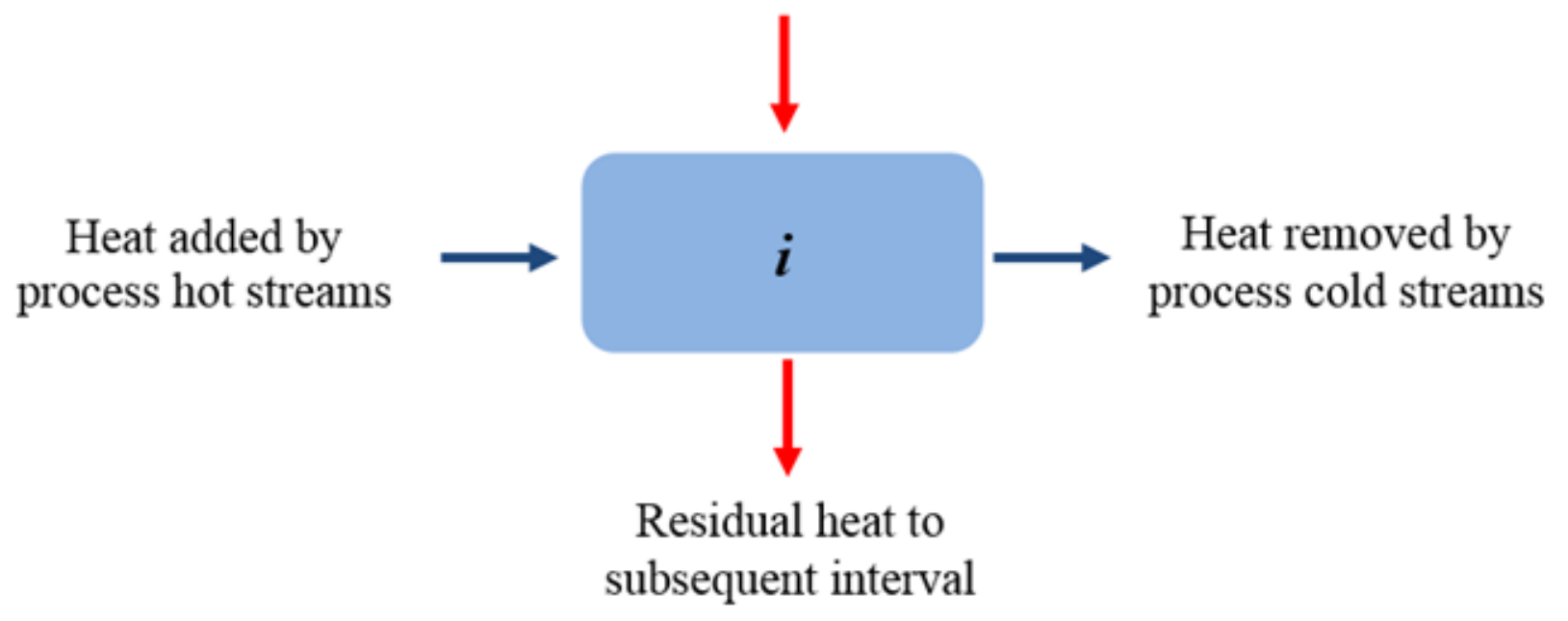

Figure 2. Heat balance around temperature interval. Source: $\operatorname{In}^{17}$ 
stream that passes through each temperature interval is calculated by Eq. 3 .

$$
H C=f_{v} c_{p, v}\left(t_{i}-t_{i-1}\right)
$$

The collective loads of cold and hot streams were determined by summing up individual loads in each interval. Then, an energy balance was performed in each interval as defined by Eq. 4 .

$$
r_{i}=H H_{i}^{\text {total }}-H C_{i}^{\text {total }}+r_{i-1}
$$

Where and are residual heats entering and leaving the interval. There are not process streams above the first interval, therefore, . The heat balance around a temperature interval is pointed out by El-Halwagi ${ }^{17}$ and shown in Figure 2. The thermal pinch point is located in zero residual heat and provides information about minimum utilities requirements for heating and cooling.

\section{Results and Discussion}

Heat integration by thermal pinch diagram technique applied to biodiesel production reduces the requirements of heating and cooling utilities. Table 1 summarizes cold and hot streams considered in this approach.

It is important to point out that heat capacity was assumed as constant and mass flow entering to heat exchanger was considered equal to outlet mass flow. Cascade diagram was constructed to determine minimum cooling and heating utilities and the maximum integrated heat exchange, which were listed in Table 2. It was found that hot process streams can transfer enough heat to cold process streams that heating utility is no

\begin{tabular}{|c|c|c|c|c|}
\hline \multicolumn{2}{|c|}{ Streams } & $\mathrm{T}_{\mathrm{in}}\left[{ }^{\circ} \mathrm{C}\right]$ & $\mathrm{T}_{\text {out }}\left[{ }^{\circ} \mathrm{C}\right]$ & $\mathrm{C}\left[\mathrm{kW} /{ }^{\circ} \mathrm{C}\right]$ \\
\hline \multirow{4}{*}{ Hot } & 107 & 200 & 98 & 4.08 \\
\hline & 111 & 98 & 60 & 3.76 \\
\hline & 118 & 60 & 30 & 23.95 \\
\hline & 136 & 375.22 & 25 & 0.80 \\
\hline \multirow{3}{*}{ Cold } & 105 & 30 & 200 & 0.94 \\
\hline & 116 & 25 & 60 & 2.49 \\
\hline & 122 & 25 & 95 & 4.98 \\
\hline
\end{tabular}

Table 1. Hot and cold streams for biodiesel production process

Table 2. Cascade diagram results

\begin{tabular}{cccc}
\hline Utility & $\begin{array}{c}\text { Base case } \\
{[\mathrm{kW}]}\end{array}$ & $\begin{array}{c}\text { Minimum utility usage } \\
{[\mathrm{kW}]}\end{array}$ & $\begin{array}{c}\text { Maximum integrated heat } \\
\text { exchange }[\mathrm{kW}]\end{array}$ \\
\hline Heating & 602.31 & 0 & 602.31 \\
Cooling & 1558.58 & 944.98 & 613.6 \\
\hline
\end{tabular}




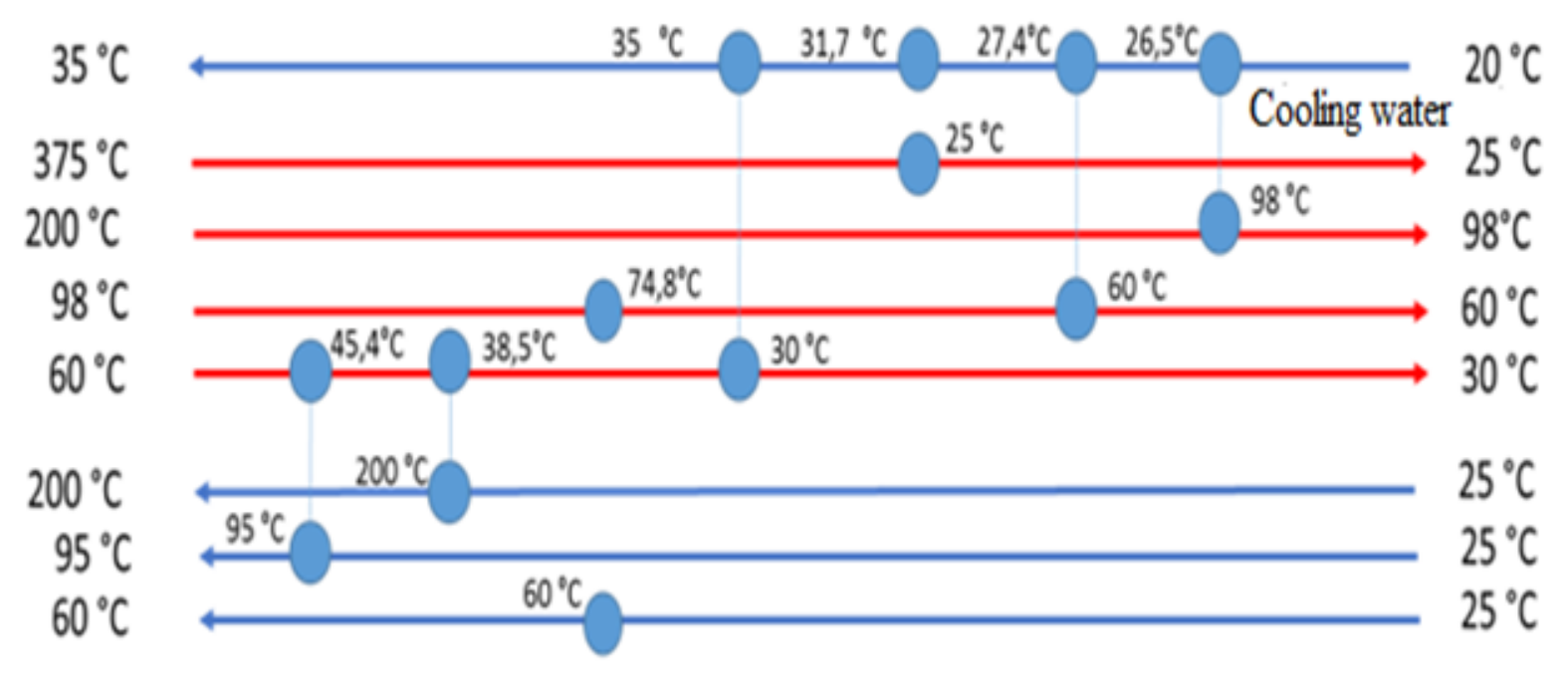

Figure 3. Heat exchange network for biodiesel production process.

required and cooling utility is reduced by $38.67 \%$ from $1558.58 \mathrm{~kW}$ to $944.98 \mathrm{~kW}$.

The pinch point was located in temperature interval with highest process stream temperature $\left(365^{\circ} \mathrm{C}\right)$, in which heat balance becomes zero. After applying heat integration, a Heat Exchange Network (HEN) with seven heat exchangers was designed for minimum utility usage. Figure 3 shows stream matching above and below the pinch point.

\section{Conclusions}

In this work, heat integration by thermal pinch point technique was studied in order to determine minimum utility usage. The results showed that HEN design for heat integration of third-generation biodiesel production process reduced cooling utilities and heating utilities by 38.67 and $100 \%$, respectively, which represents a total reduction in operating cost up to $55 \%$ in comparison to energy requirements of base case. Different HEN's can be designed; however, the HEN purposed in this research exhibited low external utilities usage and number of heat exchanger. Heat capacity of process stream played an important role on determining how many heat exchanger were required to achieve target temperature; the stream 118 (highest heat capacity) demanded more equipment than stream 136 (lowest heat capacity). These results suggested that conventional biodiesel production from Chlorella vulgaris can be improved from an energetic point of view by applying heat integration.

\section{Acknowledgments}

The authors thank to University of Cartagena for providing equipment and software necessary to successfully conclude this research.

\section{References}

1. Aminul M, Heimann K, Brown R. Microalgae biodiesel: Current status and future needs for engine performance and emissions, Renewable and Sustainable Energy Reviews. 2017; 79:1160-70. Crossref.

2. Sivaramakrishnan $R$, Incharoensakdi A. Utilization of microalgae feedstock for concomitant production of bioethanol and biodiesel, Fuel. 2018; 217:458-66. Crossref.

3. Tyagi R, Manchanda T, Sharma D. Application of $\mathrm{NaCl}$ for Biodiesel Components Production by Botryococcusbraunii, Indian Journal of Science and Technology. 2017; 10:1-5. Crossref.

4. Sanniyasi E, Prakasam V, Selvarajan R. Optimization of abiotic conditions suitable for the production of biodiesel from Chlorella vulgaris, Indian Journal of Science and Technology. 2011; 4:91-97. 
5. Martínez N, Callejas N, Morais EG, Vieira Costa JA, Jachmanián I, Vieitez I. Obtaining biodiesel from microalgae oil using ultrasound-assisted in-situ alkaline transesterification, Fuel. 2017; 202:512-19. Crossref.

6. Correa DF, Beyer $\mathrm{H}$, Possingham H, Thomas-hall S, Schenk M. Biodiversity impacts of bioenergy production: Microalgae vs, First Generation Biofuels. Renewable and Sustainable Energy Reviews. 2017; 74:1131-46. Crossref.

7. Boutesteijn C, Drabik D, Venus T. The interaction between EU biofuel policy and first- and second-generation biodiesel production, Industrial Crops and Products. 2016; 106:124-29. Crossref.

8. Saladini F, Patrizi N, Pulselli FM, Marchettini N, Bastianoni S. Guidelines for energy evaluation of first, second and third generation bio-fuels, Renewable and Sustainable Energy Reviews. 2016; 66:221-27. Crossref.

9. Tan X, Uemura Y, Lim JW, Wong CY, Lee T. Cultivation of microalgae for biodiesel production: A review on upstream and downstream processing, Chinese Journal of Chemical Engineering. 2017; 26:17-30. Crossref.

10. Torres S, Acien G, García-cuadra F, Navia R. Direct transesterification of microalgae biomass and biodiesel refining with vacuum distillation, Algal Research. 2017; 28:30-38. Crossref.
11. Sanguino-Barajas P, Barajas-Solano A, Urbina-Suarez N, Gonzalez-Delgado A, Barajas-Ferreira C. Development of a selective method for metabolites extraction from microalgae biomass, Indian Journal of Science and Technology. 2018; 11:1-18. Crossref.

12. Muradovich M. Foresight of microalgae usage for the production of third-generation bio-fuel, Indian Journal of Science and Technology. 2017; 10:1-10.

13. Nwokoagbara E, Olaleye AK, Wang M. Biodiesel from microalgae: The use of multi-criteria decision analysis for strain selection, Fuel. 2015; 159:241-49. Crossref.

14. Gupta S Sen, Shastri Y, Bhartiya S. Model-based optimization of biodiesel production from microalgae, Computers and Chemical Engineering. 2016; 89:222-49. Crossref.

15. Song C, Chen G, Ji N, Liu Q, Kansha Y, Tsutsumi A. Biodiesel production process from microalgae oil by waste heat recovery and process integration, Bio-resource Technology. 2015; 193:192-99. Crossref.

16. Faried M, Samer M, Abdelsalam E, Yousef R, Attia Y, Ali A. Biodiesel production from microalgae: Processes, technologies and recent advancements, Renewable and Sustainable Energy Reviews. 2017; 79:893-913. Crossref.

17. El-Halwagi M. Process Integration. Elsevier, Academic Press; 2006. p. 1-414. 